\title{
Management of deep looping when failing to progress at double-balloon enteroscopy
}

Deep intubation of the small bowel during double-balloon enteroscopy (DBE), as described by Yamamoto et al. [1 - 3], relies on the principles of minimal small-bowel stretching and loop reduction. This is achieved by simultaneous traction provided by the enteroscope and overtube balloons, combined with a "pullback" maneuver that allows loop resolution and straightening of the free and untethered small bowel [1]. In our experience and that of others [4], this insertion method may be unsuccessful, for example when small-bowel tethering due to intraabdominal adhesions occurs in patients, because deep loops are formed that are difficult to reduce when the enteroscope is advanced. The result is a decreased insertion depth and a higher rate of failure for the procedure. We describe an adaptation of the conventional insertion method that may be useful when deep looping occurs during DBE.

Step 1: Progress is hindered (e.g. because of a fixed mesentery or small-bowel tethering) resulting in the formation of a deep loop on enteroscope advancement ( $\mathbf{F i g} .1 \mathbf{i}$ ). The loop is stabilised by the inflated enteroscope balloon as the overtube is advanced with its balloon deflated (॰ Fig. 1 ii).

Step 2: The overtube balloon is inflated and the overtube is pulled back as the enteroscope is advanced through the loop with its balloon deflated ( Fig. 2).

Step 3: The enteroscope is pulled back with its balloon inflated as the overtube is advanced with its balloon deflated. This step is key to the success of this variation in insertion method and relies on the use of the enteroscope balloon alone (which is not available in other deep enteroscopy techniques such as single-balloon or spiral enteroscopy) ( $\mathbf{F i g . 3}$ ).

Step 4: The overtube balloon is inflated and the enteroscope with its balloon deflated is advanced through the partially reduced deep loop as the overtube is pulled back ( $\bullet$ Fig. 4).

Endoscopy_UCTN_Code_TTT_1AP_2AD

Competing interests: Education and Research Grant (Imotech Medical/Fujinon)

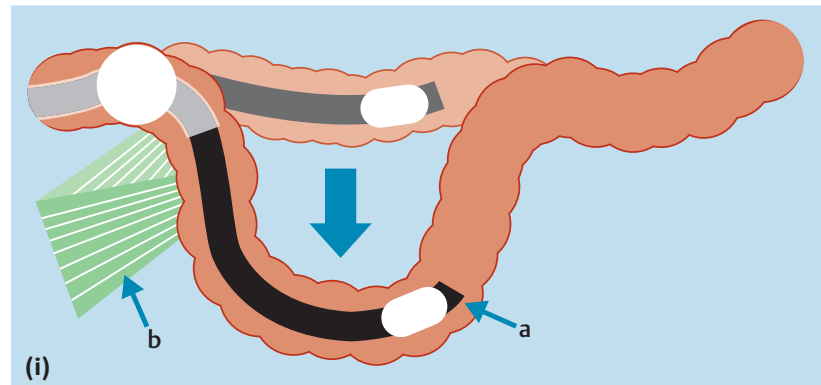

Fig. 1 (i) Failure to progress with the enteroscope (a) as fixed mesentery forms a deep loop (b). (ii) The enteroscope balloon is inflated (a), the overtube balloon is deflated (b), and the overtube is advanced (c).
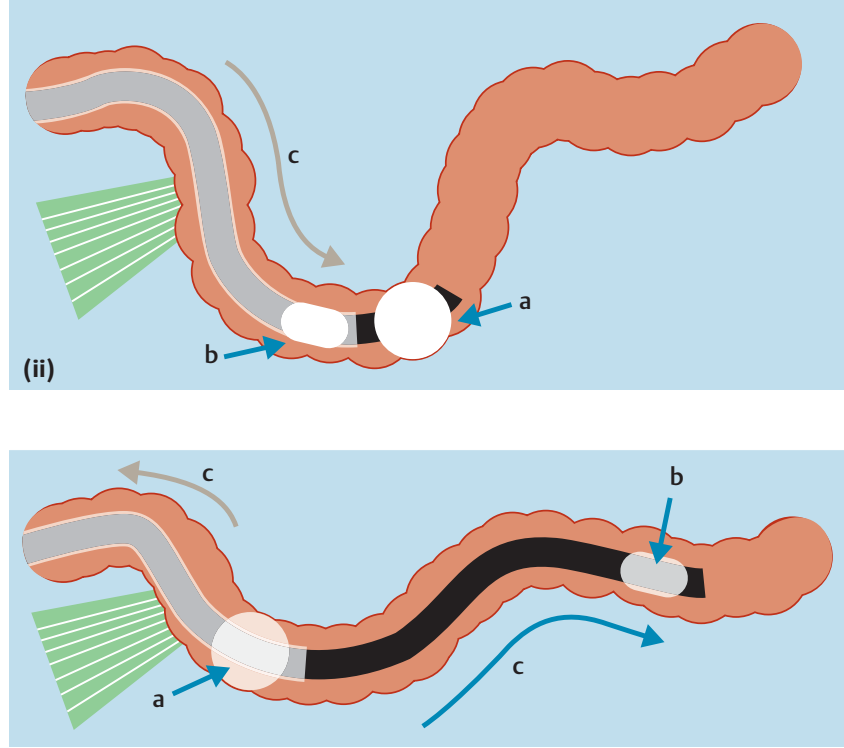

Fig. 2 The overtube balloon is inflated (a), the enteroscope balloon is deflated (b), and the enteroscope is advanced as the overtube is pulled back (c).

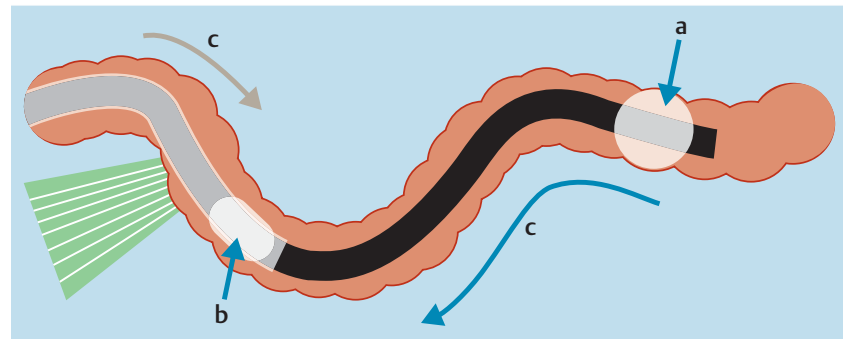

Fig. 3 The enteroscope balloon is inflated (a), the overtube balloon is deflated (b), and the overtube is advanced as the enteroscope is pulled back (c).

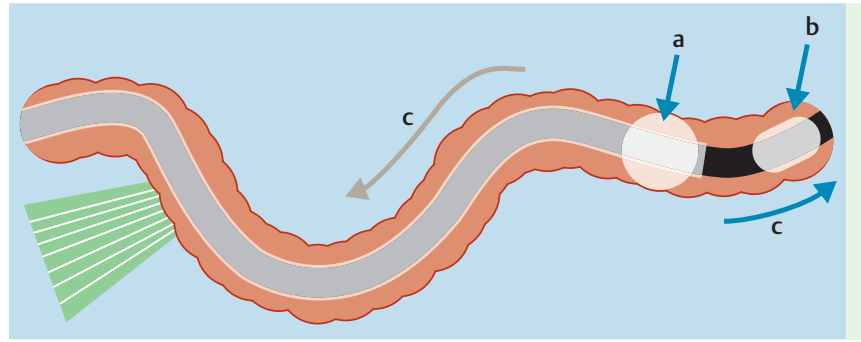

Fig. 4 The overtube balloon is inflated (a), the enteroscope balloon is deflated (b), and the enteroscope is advanced as the overtube is pulled back (c). 


\section{E. J. Despott, A. Murino, C. Fraser}

The Wolfson Unit for Endoscopy, St Mark's Hospital and Academic Institute, Imperial College London, London, UK

\section{References}

1 Sugano K, Yamamoto H, Kita H. Double-balloon endoscopy theory and practice. 1st edn. Tokyo: Springer; 2006

2 Yamamoto H, Sekine Y, Sato Y et al. Total enteroscopy with a nonsurgical steerable double-balloon method. Gastrointest Endosc 2001; 53: 216-220

3 Yamamoto H, Sugano K. A new method of enteroscopy - the double-balloon method. Can J Gastroenterol 2003; 17: 273 - 274

4 Gerson LB, Flodin JT, Miyabayashi K. Balloonassisted enteroscopy: technology and troubleshooting. Gastrointest Endosc 2008; 68: $1158-1167$

\section{Bibliography}

DOI $10.1055 / \mathrm{s}-0030-1256387$

Endoscopy 2011; 43: E275-E276

(c) Georg Thieme Verlag KG Stuttgart · New York . ISSN 0013-726X

\section{Corresponding author}

\section{Fraser, MD}

The Wolfson Unit for Endoscopy

St Mark's Hospital and Academic Institute

Imperial College London (Northwick Park Campus)

Watford Road

Harrow

London

HA1 3U]

UK

Fax: +44-208-423358

chris.fraser@imperial.ac.uk 